\title{
KIF4A knockdown suppresses ovarian cancer cell proliferation and induces apoptosis by downregulating BUB1 expression
}

\author{
WUMIN JIN $^{1}$ and LIANMIN YE ${ }^{2}$ \\ ${ }^{1}$ Reproductive Medicine Center and ${ }^{2}$ Department of Intensive Care Unit, The First Affiliated Hospital \\ of Wenzhou Medical University, Wenzhou, Zhejiang 325000, P.R. China
}

Received August 4, 2020; Accepted January 4, 2021

DOI: $10.3892 / \mathrm{mmr} .2021 .12155$

\begin{abstract}
Ovarian cancer is one of the most common lethal gynecological malignancies worldwide. Abnormal kinesin family member 4A (KIF4A) expression has been implicated in ovarian cancer progression; however, the potential mechanism underlying KIF4A in ovarian cancer is not completely understood. The present study aimed to clarify the molecular basis of KIF4A in ovarian cancer. KIF4A and budding uninhibited by benzimidazoles 1 (BUB1) expression levels were detected via reverse transcription-quantitative PCR and western blotting. Cell Counting Kit-8, colony formation, wound healing, TUNEL and flow cytometry assays were performed to assess cell proliferation, migration, apoptosis and cell cycle distribution, respectively. Ki67 expression levels were detected by conducting immunofluorescence assays. The expression levels of migration- and apoptosis-related proteins were measured via western blotting. A co-immunoprecipitation assay was conducted to determine the association between KIF4A and BUB1. The results demonstrated that KIF4A was expressed at significantly higher levels in ovarian cancer cell lines compared with IOSE-80 cells. Compared with the short hairpin RNA-negative control group, KIF4A knockdown significantly inhibited cell viability, colony formation and migration, and markedly induced cell apoptosis. The results indicated that KIF4A could bind to BUB1 and regulate BUB1 expression. BUB1 overexpression weakened KIF4A knockdown-mediated effects on cell viability, colony formation, migration and apoptosis. Overall, the present study demonstrated that KIF4A knockdown suppressed ovarian cancer progression by regulating BUB1, and suggested the potential value of KIF4A and BUB1 as therapeutic targets for ovarian cancer.
\end{abstract}

Correspondence to: Dr Lianmin Ye, Department of Intensive Care Unit, The First Affiliated Hospital of Wenzhou Medical University, 3 Nanbaixiang Street, Ouhai, Wenzhou, Zhejiang 325000, P.R. China E-mail:1myeun@126.com

Key words: ovarian cancer, kinesin family member 4A, budding uninhibited by benzimidazoles 1 , proliferation, apoptosis

\section{Introduction}

Ovarian cancer is one of the most common lethal gynecological malignancies worldwide, with $\sim 240,000$ newly diagnosed cases each year globally (1). In 2018, ovarian cancer was the fifth leading cause of cancer-associated mortality in women, and the second most common malignancy after breast cancer in women aged $>40$ years, particularly in developed countries $(2,3)$. Although progress in surgical resection and aggressive treatment with chemotherapy and radiotherapy has been achieved in recent years, at present, there are no satisfactory treatments for patients with late-stage disease; thus, the prognosis of ovarian cancer remains poor (4). Therefore, identifying the mechanisms underlying the progression of ovarian cancer is important for the discovery of novel molecular targets for diagnosis and treatment.

Kinesin (KIF) superfamily proteins are microtubuledependent molecular motors that exert multiple functions in intracellular transport and cell division (5). Kinesin family member 4A (KIF4A), a KIF protein, is an essential chromosome-associated molecular motor encoding a $140-\mathrm{kDa}$ protein (6). Previous studies have revealed that KIF4A is involved in various functions, including controlling chromosome condensation and segregation, middle-spindle formation and cytokinesis during mitotic division (7-9). Furthermore, previous studies have demonstrated that KIF4A functions as an oncogene and serves crucial roles in several malignancies, including colorectal (10), breast (11) and prostate cancer (12), as well as hepatocellular carcinoma (13). Yang et al (14) identified abnormal expression levels of KIF4A using ovarian cancer tissue data obtained from the Gene Expression Omnibus database, and revealed that patients with ovarian cancer with high KIF4A expression were more likely to experience poor progression-free survival, indicating that KIF4A may be involved in the pathogenesis of ovarian cancer. However, the precise roles and mechanisms underlying KIF4A in ovarian cancer are not completely understood.

Budding uninhibited by benzimidazoles 1 (BUB1) is a mitotic checkpoint serine/threonine kinase that serves a critical role in mitosis by phosphorylating members of the mitotic checkpoint complex and activating the spindle checkpoint (15). Since BUB1 expression is upregulated in several types of cancer, including gastric and prostate cancer, and is closely associated with poor patient outcomes, emerging studies 
have recognized BUB1 as an oncogene in tumors of diverse origins $(16,17)$. Notably, a potential interaction of KIF4A and BUB1 has been predicted using Search Tool for the Retrieval of Interacting Genes/Proteins (18). A bioinformatics analysis conducted by Feng et al (19) identified upregulated expression levels of BUB1 in ovarian cancer, which were associated with poor prognosis. The aforementioned results indicated that BUB1 might be involved in the progression of ovarian cancer, which might also be associated with KIF4A.

The present study examined the expression levels of KIF4A and BUB1, and their biological significance in ovarian cancer cells, which provided a potential therapeutic target for ovarian cancer.

\section{Materials and methods}

Bioinformatics analysis. Data from Gene Expression Profiling Interactive Analysis (GEPIA; http://gepia2021.cancer-pku.cn/ index.html) database, which is a valuable and highly cited resource for gene expression analysis based on tumor and normal samples from The Cancer Genome Atlas and The Genotype-Tissue Expression databases, including 426 ovarian cancer tumor samples and 88 normal samples, were used to analyze the expression levels of KIF4A.

Cell culture. The normal ovarian cell line (IOSE-80) was obtained from Shanghai Yaji Biotechnology Co., Ltd. The human ovarian cancer cell lines (ES-2, SKOV3, OVCAR3 and HEY-T30) were purchased from American Type Culture Collection. A2780 cells were purchased from BeNa Culture Collection (Beijing Beina Chunglian Biotechnology Research Institute). IOSE-80, ES-2, HEY-T30 and SKOV3 cells were cultured in RPMI-1640 (Biological Industries) supplemented with 10\% FBS (Gibco; Thermo Fisher Scientific, Inc.) and 1\% penicillin/streptomycin. OVCAR3 and A2780 cells were cultured in DMEM (Gibco; Thermo Fisher Scientific, Inc.) supplemented with $10 \%$ FBS and 1\% penicillin/streptomycin. All cells were cultured at $37^{\circ} \mathrm{C}$ in a $5 \% \mathrm{CO}_{2}$ incubator.

Reverse transcription-quantitative PCR (RT-qPCR). Total RNA was extracted from cells using TRIzol ${ }^{\circledR}$ reagent (Invitrogen; Thermo Fisher Scientific, Inc.). RNA concentration and quality were measured at an absorbance of 260/280 using a Nanodrop ND-100 spectrophotometer (Thermo Fisher Scientific, Inc). Subsequently, RNA was reverse transcribed into cDNA using the PrimeScript RT reagent kit (Takara Biotechnology Co., Ltd.) according to the manufacturer's protocol. qPCR was performed using SYBR Green PCR Master Mix (Applied Biosystems; Thermo Fisher Scientific, Inc.) according to the manufacturer's protocol. The thermocycling conditions were as follows: $94^{\circ} \mathrm{C}$ for $5 \mathrm{~min}$, 40 cycles of $94^{\circ} \mathrm{C}$ for $15 \mathrm{sec}, 60^{\circ} \mathrm{C}$ for $25 \mathrm{sec}$ and $72^{\circ} \mathrm{C}$ for $30 \mathrm{sec}$. The sequences of the gene primers were as follows: KIF4A forward, 5'-CTGCAATTGGTTGGCGTCTC-3' and reverse, 5'-CAGCGCCACTCTTACAGGAA-3'; BUB1 forward, 5'-TGGGAAAGATACATACAGTGGGT-3' and reverse, 5'-AGGGGATGACAGGGTTCCAAT-3'; and $\beta$-actin forward, 5'-GGCACCCAGCAATGAA-3' and reverse, 5'-TAGAAGCATTTGCGGTGG-3'. mRNA expression levels were quantified using the $2^{-\Delta \Delta \mathrm{Cq}}$ method (20) and normalized to the internal reference gene $\beta$-actin.

Western blotting. Total protein was extracted from cells using RIPA buffer containing protease inhibitor (Beyotime Institute of Biotechnology). Following quantification using a BCA assay, proteins (30 $\mu \mathrm{g} /$ lane) were separated via $12 \%$ SDS-PAGE, and subsequently transferred to PVDF membranes. Following blocking with $5 \%$ skimmed milk at room temperature for $2 \mathrm{~h}$, the membranes were incubated at $4^{\circ} \mathrm{C}$ overnight with primary antibodies (all purchased from Abcam) targeted against: KIF4A (1:1,000; cat. no. ab124903), BUB1 (1:2,000; cat. no. ab9000), matrix metallopeptidase (MMP)2 (1:1,000; cat. no. ab92536), MMP9 (1:1,000; cat. no. ab38898), Bcl-2 (1:1,000; cat. no. ab196495), Bax (1:1,000; cat. no. ab182733), cleaved caspase3 (1:500; cat. no. ab32042), caspase3 (1:500; cat. no. ab13847) and GAPDH (1:1,000; cat. no. ab181603). Subsequently, the membranes were incubated with HRP-conjugated goat anti-rabbit (1:5,000; cat. no. sc-2004; Santa Cruz Biotechnology, Inc.) secondary antibodies at room temperature for $2 \mathrm{~h}$. Protein bands were visualized using Pierce $^{\mathrm{TM}}$ ECL Western Blotting Substrate (Pierce; Thermo Fisher Scientific, Inc.) and semi-quantified using ImageJ software (version 1.52; National Institutes of Health).

Cell transfection. The short hairpin RNA (shRNA) against KIF4A (shRNA-KIF4A-1/2) and its negative control (shRNANC) were obtained from Shanghai GenePharma Co., Ltd. cDNA encoding BUB1 was amplified and inserted into the pcDNA3.1 vector (Shanghai GenePharma Co., Ltd.). An empty vector obtained from Shanghai GenePharma Co., Ltd., was used as the negative control (pcDNA-NC) for pcDNABUB1. OVCAR3 cells (5X105 cells/well) were transfected with $100 \mathrm{nM}$ shRNA-KIF4A1/2, pcDNA-BUB1 or the corresponding negative controls using Lipofectamine ${ }^{\circledR} 3000$ (Invitrogen; Thermo Fisher Scientific, Inc.) according to the manufacturer's protocol. Following a 48 -h incubation at $37^{\circ} \mathrm{C}$, KIF4A or BUB1 expression levels in transfected cells were determined via RT-qPCR and western blotting.

Cell proliferation assay. OVCAR3 cells were seeded into 96-well plates $\left(2 \times 10^{3}\right.$ cells/well) and cultured for 24,48 or $72 \mathrm{~h}$. At each indicated time point, $10 \mu \mathrm{l}$ Cell Counting Kit-8 (CCK-8) solution (Dojindo Molecular Technologies, Inc.) was added into each well and incubated for $2 \mathrm{~h}$ at $37^{\circ} \mathrm{C}$. The optical density of each well was measured at a wavelength of $450 \mathrm{~nm}$ using a microplate reader.

Colony formation assay. OVCAR3 cells were plated into 6 -well plates $\left(1 \times 10^{3}\right.$ cells/well) and cultured for 10 days. The culture medium was changed every 3 days. Cells were fixed in $4 \%$ paraformaldehyde for $15 \mathrm{~min}$ at room temperature and stained with $0.5 \%$ crystal violet for $30 \mathrm{~min}$ at room temperature for visualization. The number of clones (cell number $>50$ cells/colony) was counted with the naked eye or under a light microscope (low magnification).

Wound healing assay. OVCAR3 cells were plated into 6-well plates $\left(1 \times 10^{5}\right.$ cells/well). At $100 \%$ confluence, cell monolayers were scratched using a sterile $10-\mu 1$ pipette tip and washed with 
A

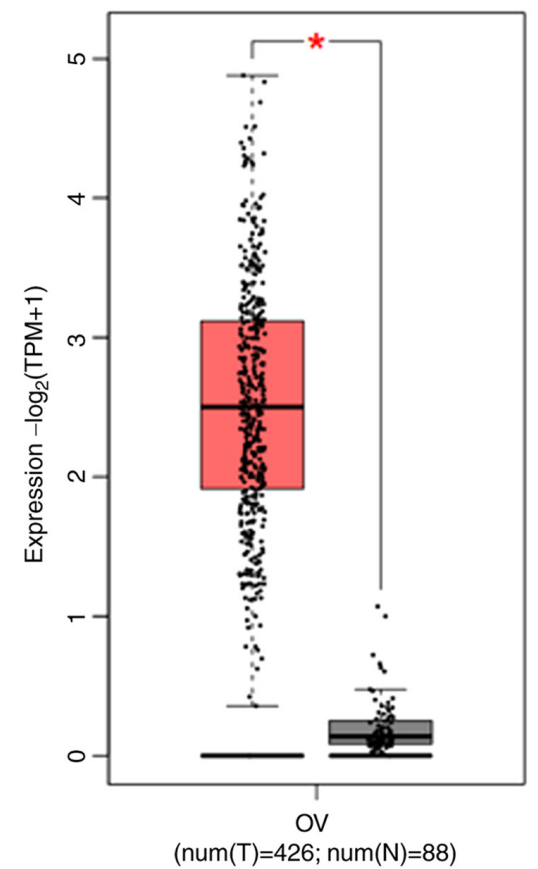

C

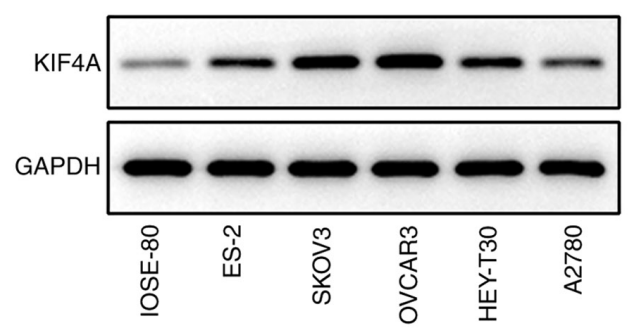

B
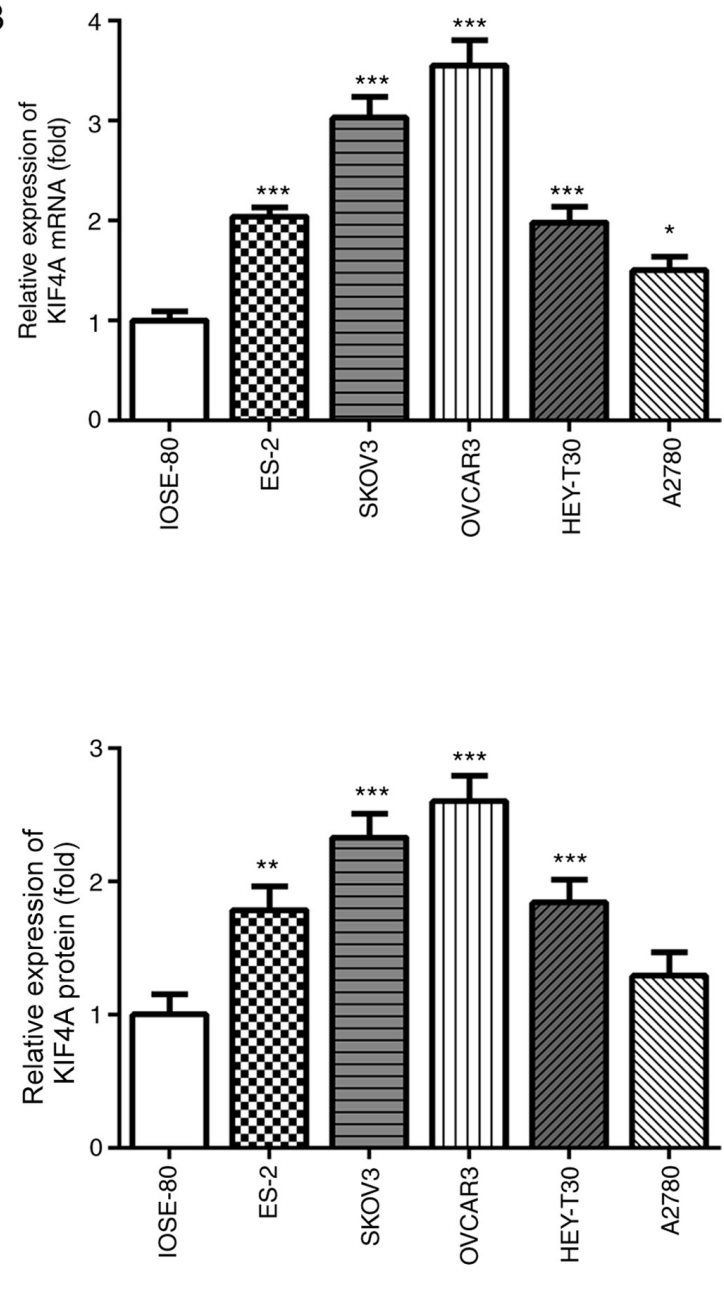

Figure 1. KIF4A expression is upregulated in ovarian cancer. (A) KIF4A expression levels in ovarian cancer tissues and healthy tissues isolated from patients. KIF4A (B) mRNA and (C) protein expression levels in the normal ovarian cell line and ovarian cancer cell lines were detected via reverse transcriptionquantitative PCR and western blotting, respectively. ${ }^{*} \mathrm{P}<0.05,{ }^{* *} \mathrm{P}<0.01$ and ${ }^{* * * *} \mathrm{P}<0.001$ vs. IOSE-80. KIF4A, kinesin family member $4 \mathrm{~A}$; T, tumor; $\mathrm{N}$, normal; TPM, transcripts per million.

PBS to remove debris. Subsequently, serum-free medium was added to the plates. Images were captured at 0 and $48 \mathrm{~h}$ using a light microscope (Leica Microsystems, Inc.). Cell migration was calculated using the following formula: Migration rate $(\%)=($ migration distance/original distance $) \times 100 \%$. The original distance was defined as the width of the wound at $0 \mathrm{~h}$, and the migration distance was defined as the difference between the width of the wound at $0 \mathrm{~h}$ and the width at $48 \mathrm{~h}$. The relative migration rate was presented as the fold-change relative to the control group.

TUNEL assay. The TUNEL assay was performed to assess cell apoptosis. After washing with PBS, cells $\left(4 \times 10^{3}\right.$ cells/well) were fixed with $4 \%$ paraformaldehyde for $10 \mathrm{~min}$ at $4^{\circ} \mathrm{C}$, and treated with $1 \%$ Triton-100 for $30 \mathrm{~min}$ at room temperature and $3 \% \mathrm{H}_{2} \mathrm{O}_{2}$ for $15 \mathrm{~min}$ at room temperature. Subsequently, a TUNEL assay kit (Roche Diagnostics) was used to detect apoptotic cells for $60 \mathrm{~min}$ at $37^{\circ} \mathrm{C}$ in the dark according to the manufacturer's protocol, followed by an incubation with DAPI for $10 \mathrm{~min}$ at room temperature in the dark. Apoptotic cells were observed and imaged using fluorescence microscopy per unit area in three fields.
Co-immunoprecipitation assay. Total protein was extracted from OVCAR3 cells using RIPA buffer containing protease inhibitor (Beyotime Institute of Biotechnology). Immunoprecipitation with specific antibodies [anti-KIF4A (1:1,000; cat. no. ab124903; Abcam) and anti-BUB1 (1:2,000; cat. no. ab9000; Abcam)] was performed as previously described (21). Immunoprecipitated protein was subjected to western blotting as aforementioned, and protein bands were visualized using Pierce ${ }^{\mathrm{TM}}$ ECL Western Blotting Substrate (Pierce; Thermo Fisher Scientific, Inc.).

Immunofluorescence. OVCAR3 cells were seeded into 24 -well plates $\left(2 \times 10^{4}\right.$ cells/well). Following culture for $48 \mathrm{~h}$, cells were fixed in $4 \%$ paraformaldehyde at $4^{\circ} \mathrm{C}$ for $30 \mathrm{~min}$ and then treated with $0.1 \%$ Triton- 100 for $15 \mathrm{~min}$ at room temperature. Cells were blocked with $5 \%$ BSA (Thermo Fisher Scientific, Inc.) at room temperature for $1 \mathrm{~h}$, followed by incubation with an anti-Ki67 primary antibody (1:200; cat. no. ab16667; Abcam) at $4^{\circ} \mathrm{C}$ overnight. Subsequently, cells were incubated with Alexa Fluor ${ }^{\circledR} 488$-conjugated secondary antibody (1:400; cat. no. A11008; Molecular Probes; Thermo Fisher Scientific, Inc.) at room temperature for $1 \mathrm{~h}$, followed 

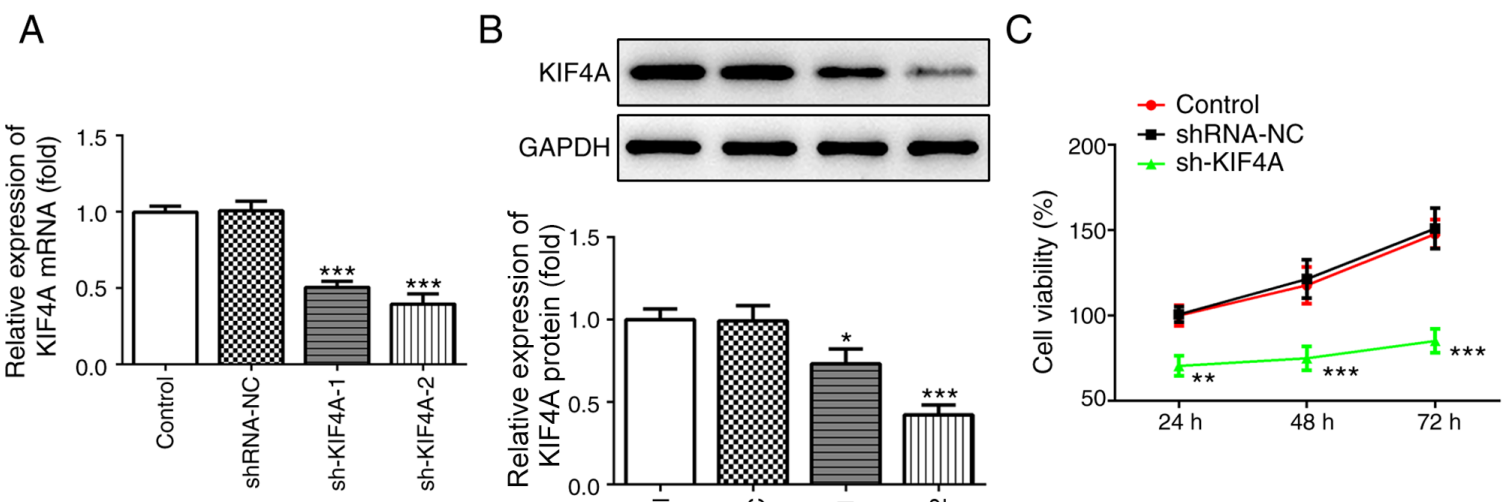

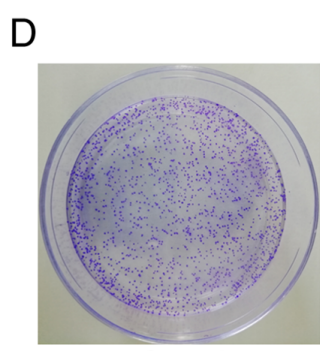

Control

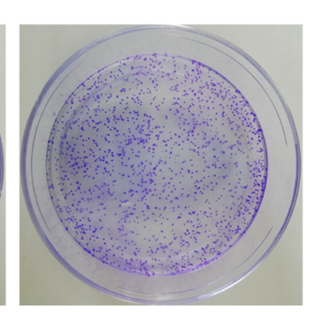

shRNA-NC

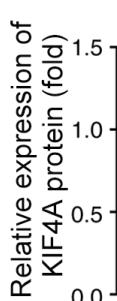

0.0
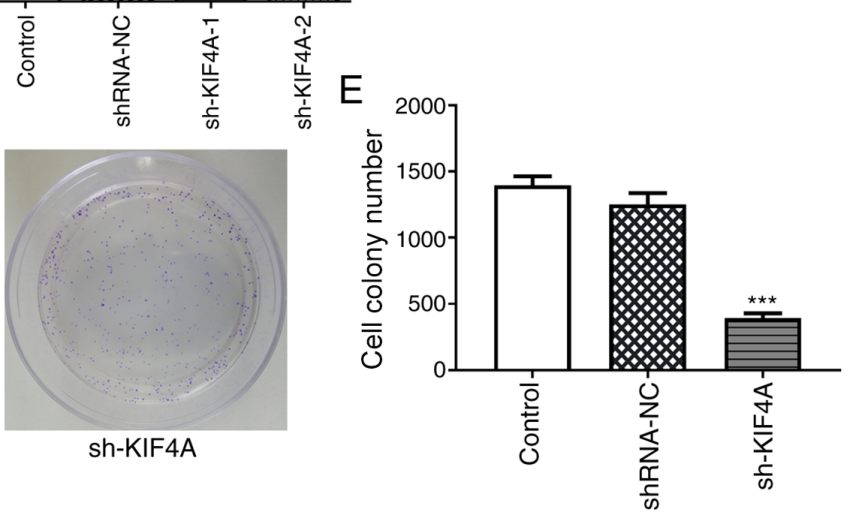

$\mathrm{F}$
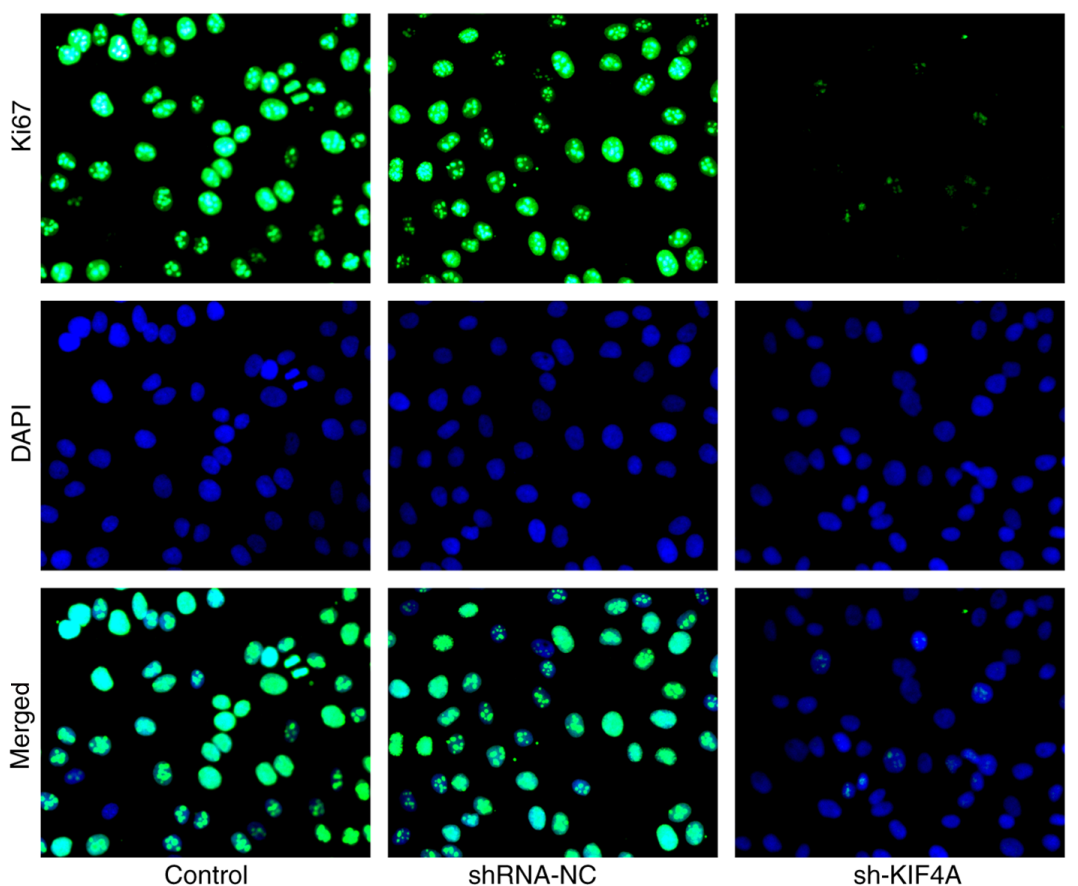

$\mathrm{G}$

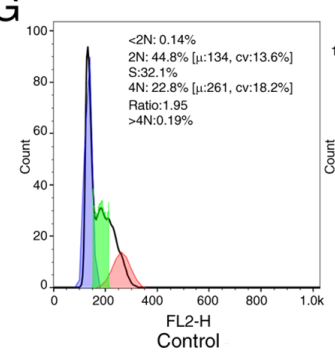

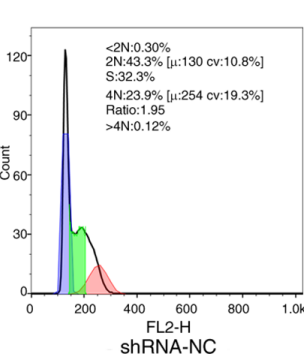

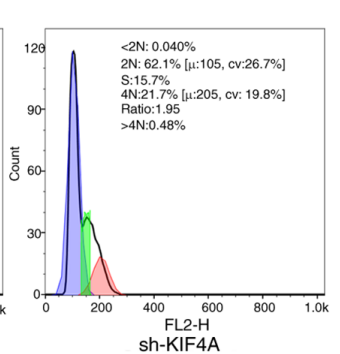

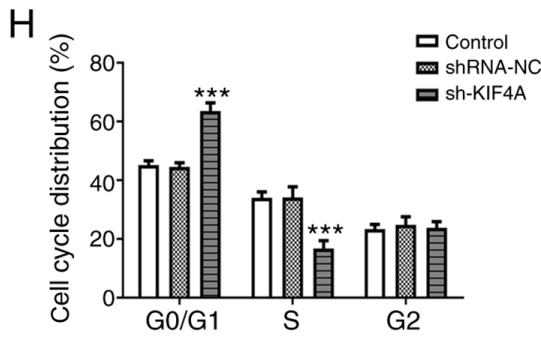

Figure 2. KIF4A knockdown suppresses cell proliferation. OVCAR3 cells were transfected with shRNA-NC and sh-KIF4A-1/2. KIF4A (A) mRNA and (B) protein expression levels were measured via reverse transcription-quantitative PCR and western blotting, respectively. (C) Cell viability was detected by performing the Cell Counting Kit-8 assay. Cell colony formation was (D) determined by performing colony formation assays and (E) quantified. Magnification, x1. (F) Ki67 expression was assessed via immunofluorescence. Magnification, $\mathrm{x} 400$. Cell cycle distributions were $(\mathrm{G})$ determined via flow cytometry and (H) quantified. ${ }^{*} \mathrm{P}<0.05,{ }^{* *} \mathrm{P}<0.01$ and ${ }^{* * *} \mathrm{P}<0.001$ vs. shRNA-NC. KIF4A, kinesin family member 4A; shRNA, short hairpin RNA; NC, negative control. 
A
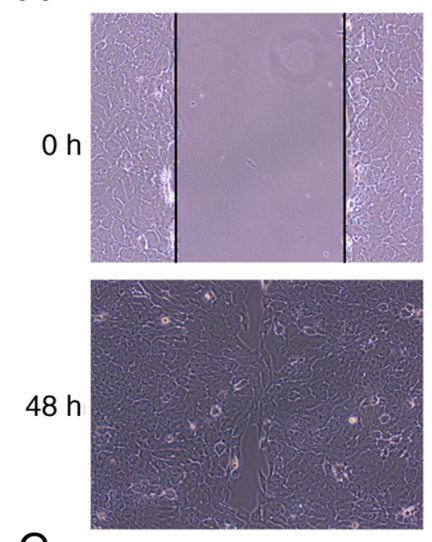

C Control
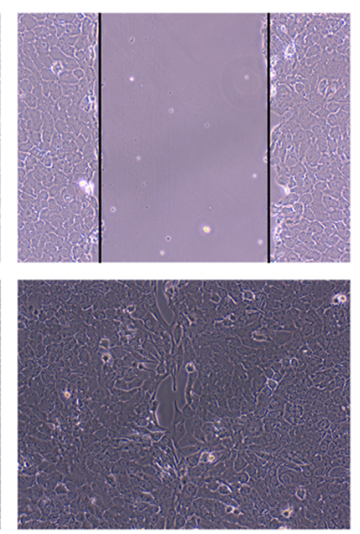

shRNA-NC
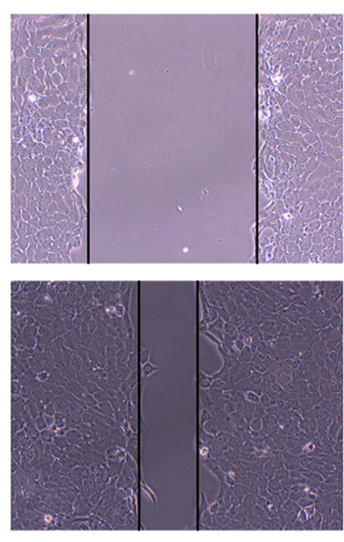

sh-KIF4A
B

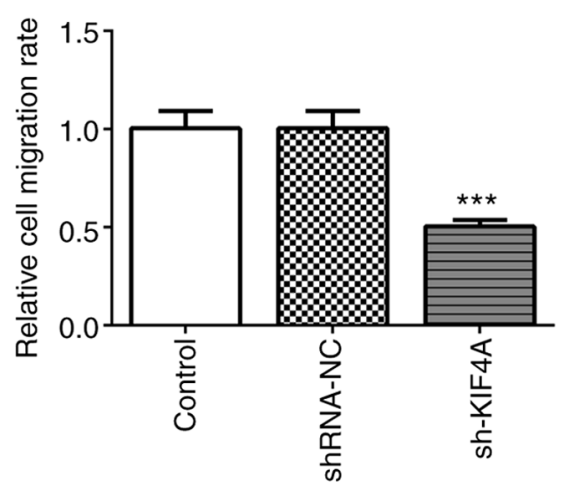

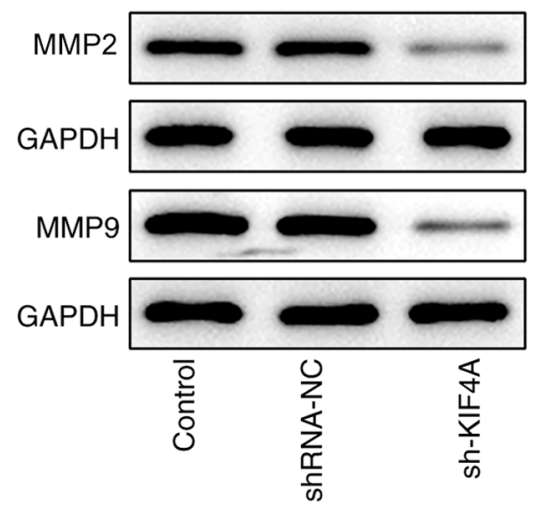
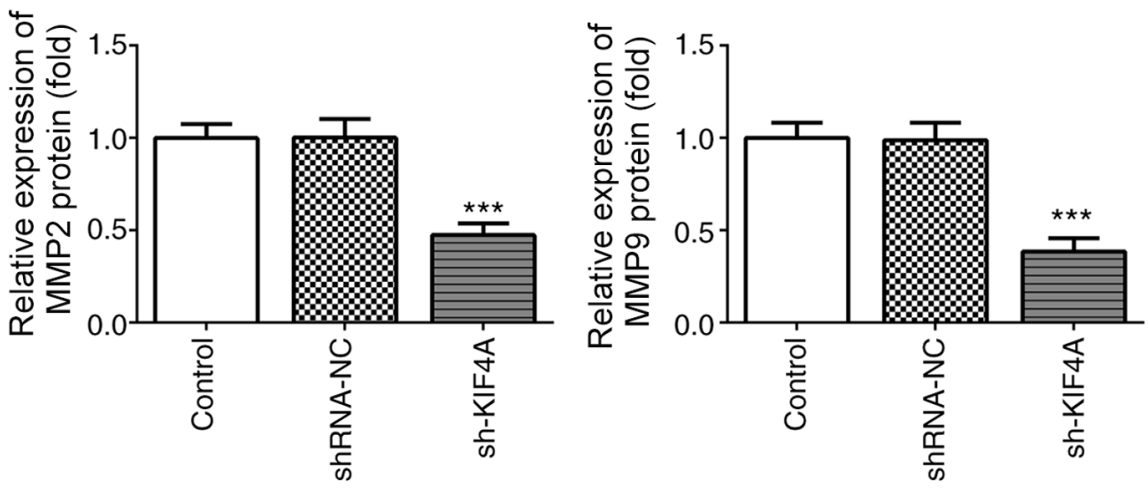

Figure 3. KIF4A knockdown suppresses cell migration ability. Cell migration was (A) assessed by performing wound healing assays and (B) quantified (C) Expression levels of migration-related proteins (MMP2 and MMP9) were detected via western blotting. Magnification, $\mathrm{x} 100 .{ }^{* * * *} \mathrm{P}<0.001 \mathrm{vs}$. shRNA-NC. KIF4A, kinesin family member 4A; MMP, matrix metallopeptidase; shRNA, short hairpin RNA; NC, negative control.

by incubation with DAPI for 3 min at room temperature in the dark. Stained sections were observed and imaged using fluorescence microscopy.

Flow cytometry assay. OVCAR3 cells were seeded into 6 -well plates ( $1 \times 10^{5}$ cells/well). At $48 \mathrm{~h}$ post-transfection, OVCAR3 cells were harvested in a centrifuge tube and fixed in $70 \%$ ethanol at $-20^{\circ} \mathrm{C}$ overnight. Following washing twice with PBS, cells were incubated with $10 \mathrm{mg} / \mathrm{ml}$ RNase A and $1 \mathrm{mg} / \mathrm{ml}$ propidium iodide in the dark at $37^{\circ} \mathrm{C}$ for $30 \mathrm{~min}$. Cell cycle distribution was analyzed using a FACSCalibur flow cytometer (BD Biosciences) with CellQuest Pro software (version 5.1; Becton, Dickinson and Company).

Statistical analysis. Statistical analyses were performed using GraphPad Prism (version 6.0; GraphPad Software, Inc.). Data are presented as the mean \pm SD from at least three experimental repeats. One-way or two-way ANOVA followed by Tukey's post hoc test were used to analyze comparisons among multiple groups. $\mathrm{P}<0.05$ was considered to indicate a statistically significant difference.

\section{Results}

KIF4A expression is upregulated in ovarian cancer. The bioinformatics analysis results using GEPIA indicated that KIF4A expression levels were significantly upregulated in ovarian cancer tumor samples compared with adjacent healthy tissues (Fig. 1A). Subsequently, KIF4A expression was detected in a normal ovarian cell line (IOSE-80) and several ovarian cancer cell lines via RT-qPCR and western blotting. KIF4A mRNA and protein expression levels were significantly higher in ovarian cancer cell lines compared with IOSE-80 cells, except KIF4A protein expression in A2780 cells (Fig. 1B and C). Among the ovarian cancer cell lines, KIF4A expression levels were highest in OVCAR 3 cells, which were selected for further experiments.

KIF4A knockdown inhibits OVCAR3 cell proliferation and migration, and promotes OVCAR3 cell apoptosis. To explore the molecular function of KIF4A in ovarian cancer, cells were transfected with sh-KIF4A-1 and sh-KIF4A-2. Compared with the shRNA-NC group, KIF4A mRNA and protein expression levels were significantly downregulated following transfection with sh-KIF4A-1 or sh-KIF4A-2 (Fig. 2A and B). Due to higher transfection efficiency, sh-KIF4A-2 was used for subsequent experiments. A series of cellular functional experiments were performed. Cell viability and colony formation were significantly inhibited by KIF4A knockdown compared with the shRNA-NC group (Fig. 2C-E). Furthermore, with increasing incubation times, the difference in cell viability between the shRNA-NC and sh-KIF4A groups increased. The immunofluorescence assay results revealed that Ki67 expression levels in the sh-KIF4A group were markedly decreased 
A
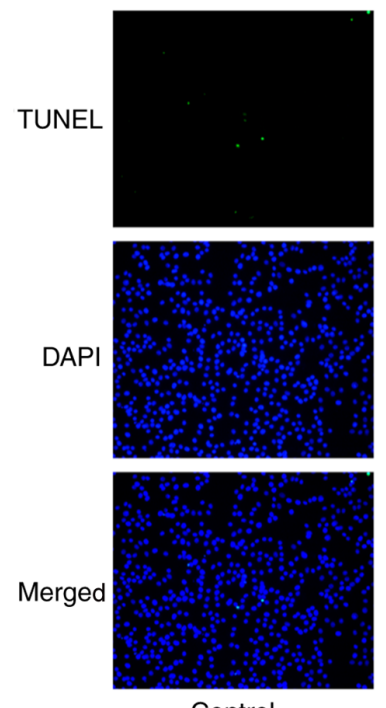

C

Control

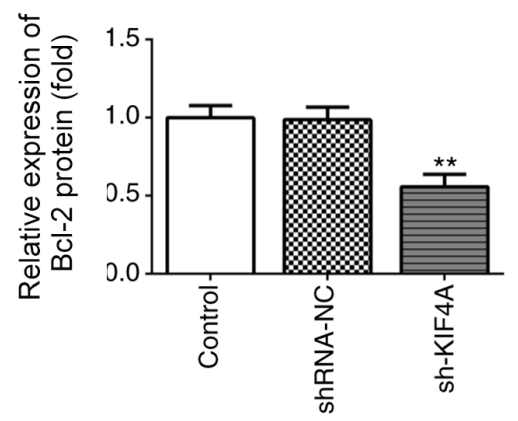

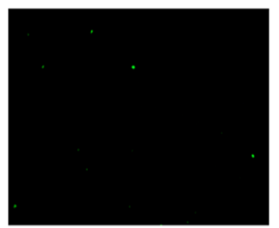
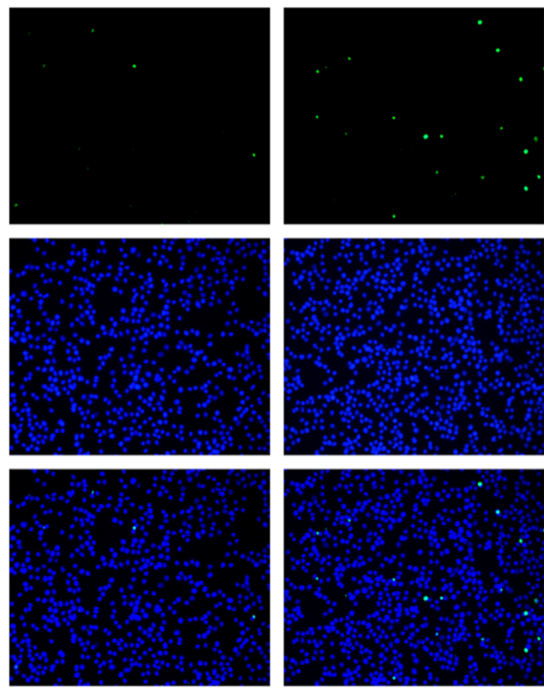

ShRNA-NC
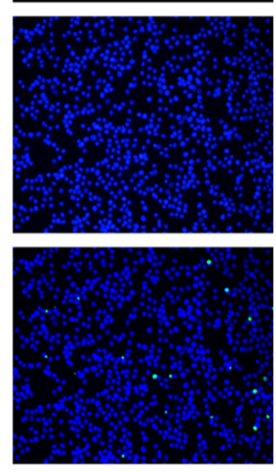

sh-KIF4A
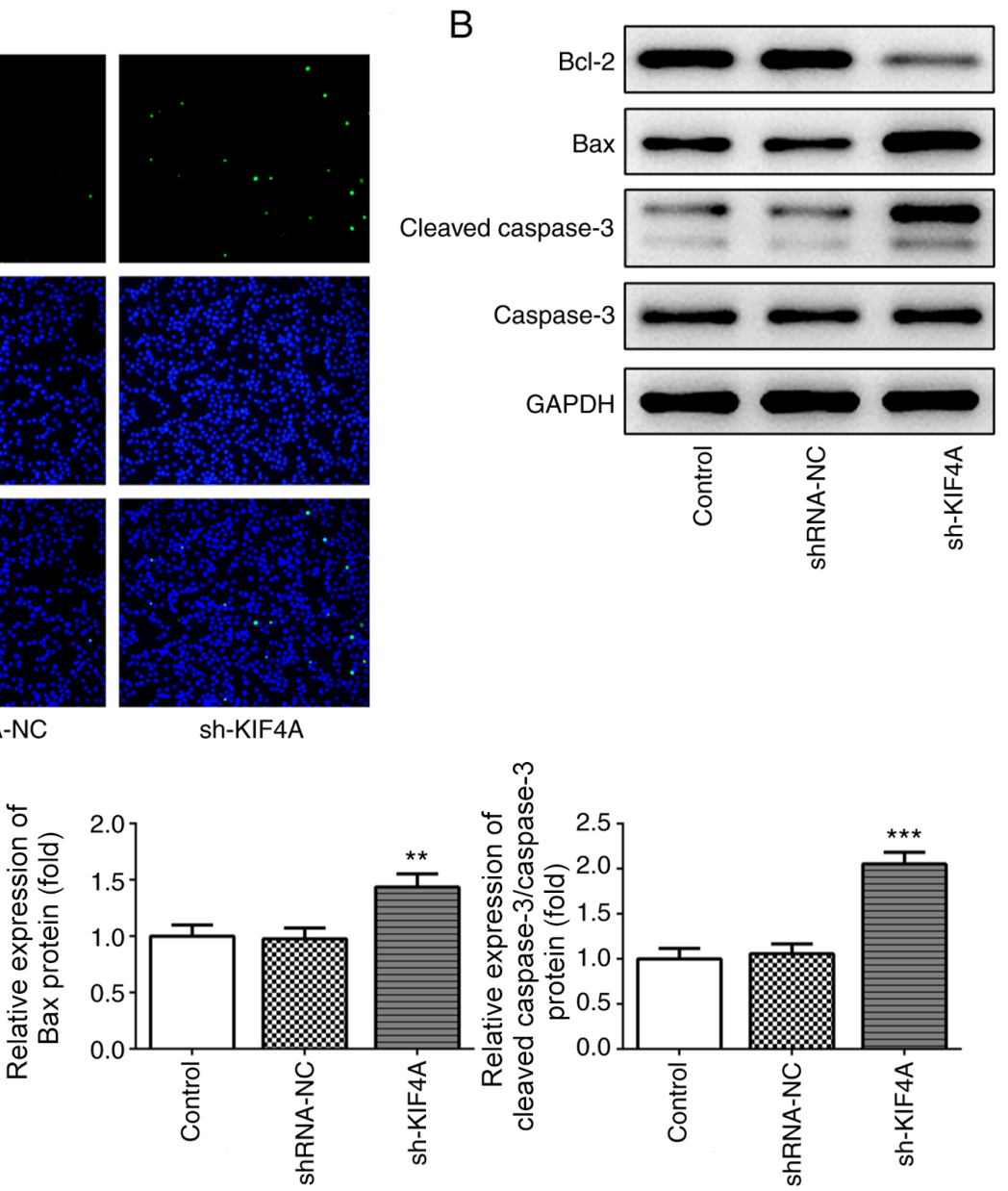

Figure 4. KIF4A knockdown promotes cell apoptosis. (A) TUNEL assays were performed to assess cell apoptosis. Magnification, x200. Apoptosis-related protein expression levels were (B) determined via western blotting and (C) semi-quantified. ${ }^{* *} \mathrm{P}<0.01$ and ${ }^{* * *} \mathrm{P}<0.001$ vs. shRNA-NC. KIF4A, kinesin family member 4A; shRNA, short hairpin RNA; NC, negative control.

compared with the shRNA-NC group (Fig. 2F). The flow cytometry assay results demonstrated that compared with the shRNA-NC group, KIF4A knockdown significantly induced cell cycle arrest at the G0/G1 phase, but significantly reduced the number of S phase cells (Fig. 2G and H). Furthermore, the wound healing assay results demonstrated that cell migration was significantly decreased by KIF4A knockdown compared with the shRNA-NC group (Fig. 3A and B), which was consistent with the decreased expression levels of MMP2 and MMP9 in KIF4A-knockdown OVCAR3 cells compared with shRNA-NC-transfected OVCAR3 cells (Fig. 3C). In addition, the TUNEL assay results demonstrated that the number of fluorescent green dots was notably increased following transfection with sh-KIF4A in OVCAR3 cells compared with the shRNA-NC group (Fig. 4A), indicating that KIF4A knockdown markedly promoted cell apoptosis. Compared with the shRNA-NC group, KIF4A knockdown significantly downregulated $\mathrm{Bcl}-2$ expression, an antiapoptotic indicator (22), whereas Bax and cleaved caspase 3 expression levels, which are proapoptotic indicators (22), were significantly upregulated (Fig. 4B and C), further demonstrating that KIF4A knockdown markedly promoted cell apoptosis.

BUB1 expression is upregulated in ovarian cancer cells and regulated by KIF4A. Subsequently, the expression levels of
BUB1 were detected in the normal ovarian cell line (IOSE-80) and several ovarian cancer cell lines. BUB1 mRNA and protein expression levels were significantly upregulated in ovarian cancer cell lines compared with IOSE-80 cells (Fig. 5A and B). The interaction of KIF4A and BUB1 was verified by performing the co-immunoprecipitation assay (Fig. 5C). Furthermore, KIF4A knockdown significantly decreased BUB1 mRNA and protein expression levels in OVCAR3 cells compared with the shRNA-NC group (Fig. 5D and E), indicating that KIF4A positively regulated BUB1 expression in ovarian cancer.

BUB1 overexpression reverses KIF4A knockdown-mediated effects on ovarian cancer cells. To further investigate the regulatory mechanism between KIF4A and BUB1 in ovarian cancer, OVCAR3 cells were transfected with pcDNA-BUB1. Following transfection with pcDNA-BUB1, BUB1 mRNA and protein expression levels were significantly increased compared with the pcDNA-NC group (Fig. 6A and B). Subsequently, OVCAR3 cells were co-transfected with sh-KIF4A and pcDNANC or pcDNA-BUB1. The CCK-8 assay results demonstrated that BUBI overexpression significantly decreased KIF4A knockdown-mediated inhibitory effects on cell viability at the 48 and 72 h time points (Fig. 6C). Additionally, BUB1 overexpression weakened KIF4A knockdown-mediated inhibitory 
A

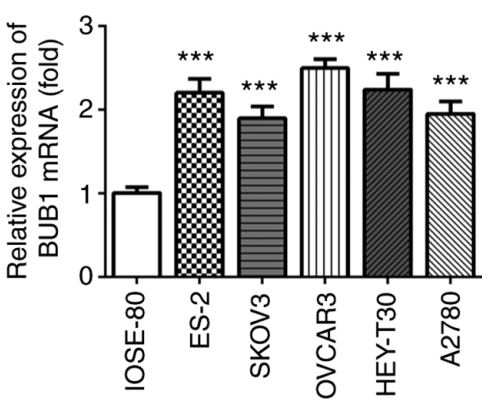

B

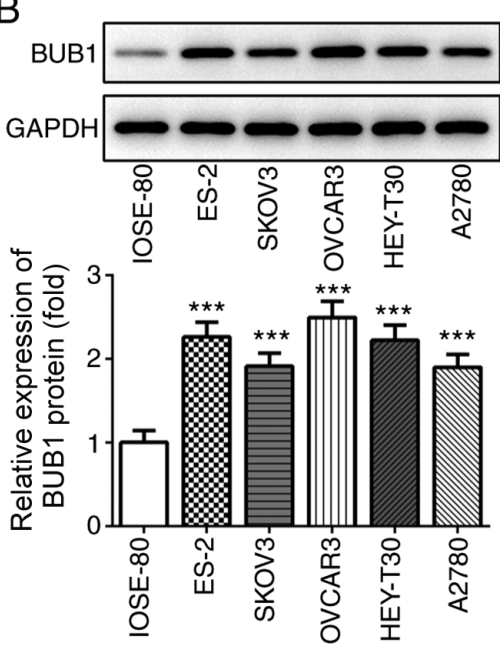

C
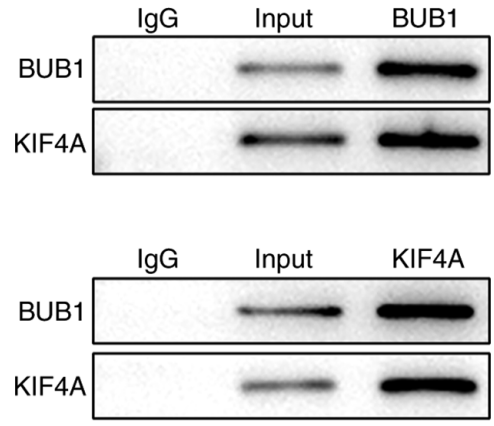

D

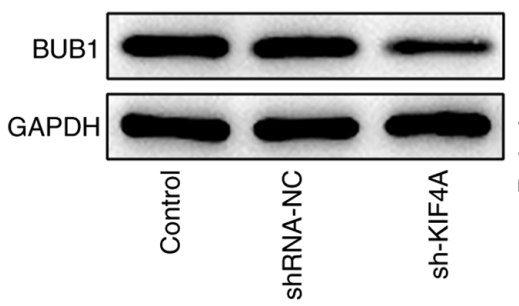

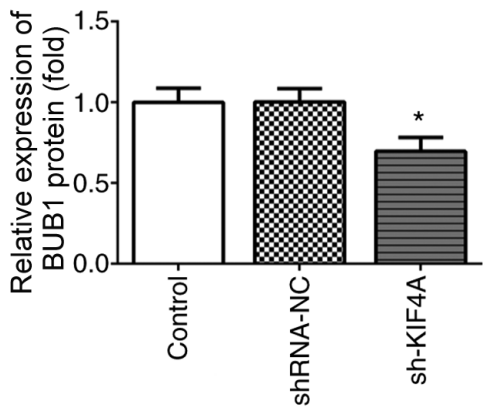

E

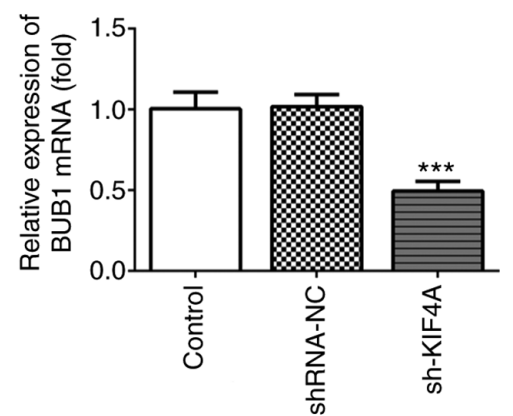

Figure 5. BUB1 is upregulated in ovarian cancer cells and regulated by KIF4A. BUB1 (A) mRNA and (B) protein expression levels in the normal ovarian cell line and ovarian cancer cell lines were detected via reverse transcription-quantitative PCR and western blotting, respectively. (C) Interactions between KIF4A and BUB1 were verified by performing the co-immunoprecipitation assay. Effect of KIF4A knockdown on BUB1 (D) protein and (E) mRNA expression levels were assessed via western blotting and reverse transcription-quantitative PCR, respectively. ${ }^{*} \mathrm{P}<0.05$ and ${ }^{* * * *} \mathrm{P}<0.001$ vs. IOSE-80 or shRNA-NC. BUB1, budding uninhibited by benzimidazoles 1; KIF4A, kinesin family member 4A; shRNA, short hairpin RNA; NC, negative control.

effects on colony formation and Ki67 expression (Fig. 6D and E), indicating that KIF4A knockdown-induced inhibition of cell proliferation was reversed by BUB1 overexpression. Furthermore, KIF4A knockdown-induced inhibition of cell migration was also reversed by BUB1 overexpression (Fig. 7A and $\mathrm{B}$ ), and KIF4A knockdown-mediated downregulation of MMP2 and MMP9 expression levels was inhibited by BUB1 overexpression (Fig. 7C). The TUNEL assay results demonstrated that the number of apoptotic cells was reduced following co-transfection with sh-KIF4A and pcDNA-BUB1 compared with transfection with sh-KIF4A alone (Fig. 8A). In addition, compared with the control group, KIF4A knockdown significantly downregulated Bcl-2 expression, but significantly upregulated Bax and cleaved caspase 3 expression levels, which was reversed by BUB1 overexpression (Fig. 8B), suggesting that BUB1 overexpression promoted cell apoptosis.

\section{Discussion}

Ovarian cancer is one of the most common lethal gynecological malignancies worldwide, accounting for $2.5 \%$ of all malignancies in women (23). Due to the vague symptoms of ovarian cancer, and the lack of early screening and detection techniques, $70-75 \%$ of patients with ovarian cancer are first diagnosed at an advanced stage (24). Therefore, identifying and understanding novel specific targets of ovarian cancer is important to improve diagnosis and therapeutic strategies. The present study demonstrated that KIF4A and BUB1 expression levels were significantly increased in ovarian cancer cell lines compared with IOSE-80 cells. Moreover, KIF4A interacted with BUB1 and positively regulated BUB1 expression. By modulating BUB1, KIF4A knockdown significantly inhibited ovarian cancer cell viability, colony formation and migration, and markedly induced cell apoptosis compared with the shRNA-NC group, hindering the development of ovarian cancer. Therefore, the present study indicated that KIF4A knockdown exerted anticancer activities in ovarian cancer; thus, KIF4A knockdown might serve as a potential therapeutic strategy for ovarian cancer.

KIF4A serves as an oncogene in various types of cancer, and KIF4A can regulate cellular functions and behaviors to influence the occurrence and development of malignancies. For example, Hou et al (10) demonstrated that KIF4A could enhance cell proliferation by promoting cell cycle progression in vivo and in vitro, contributing to the development of colorectal cancer. Hou et al (13) reported that KIF4A overexpression enhanced hepatocellular carcinoma cell proliferation and migration, whereas KIF4A knockdown reduced cell proliferation and migration, indicating the potential role of KIF4A in mediating tumor initiation and 

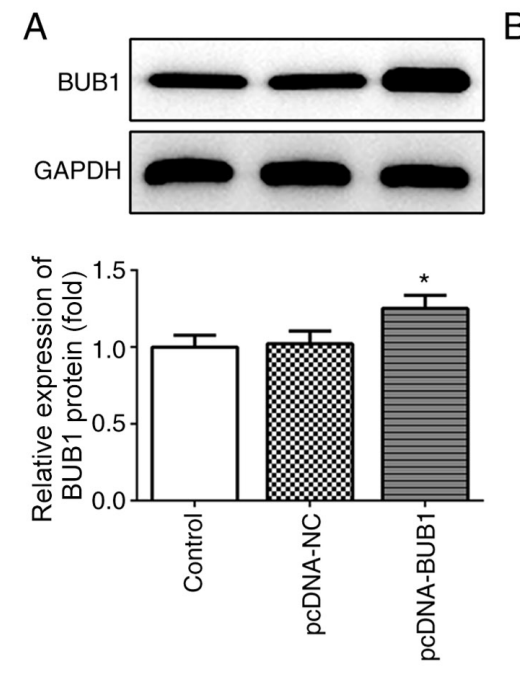

D

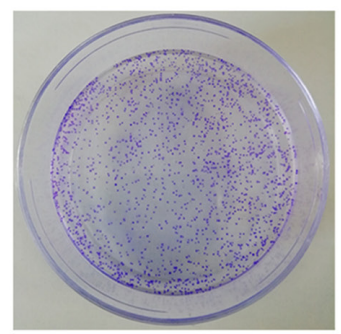

E
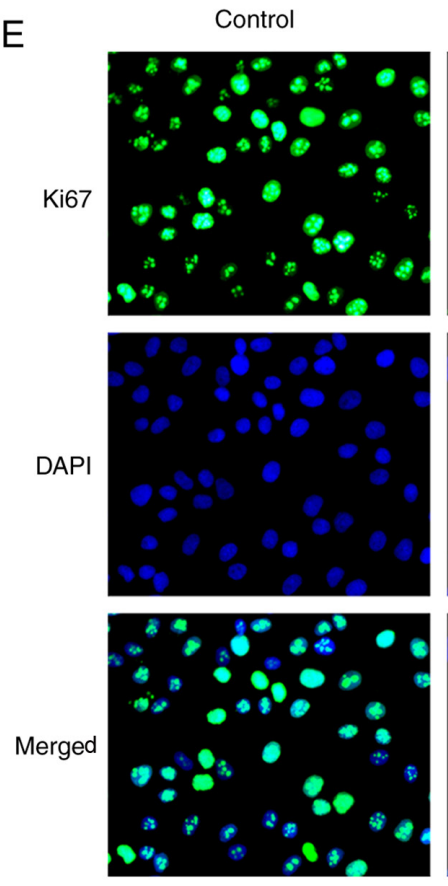

Control
B

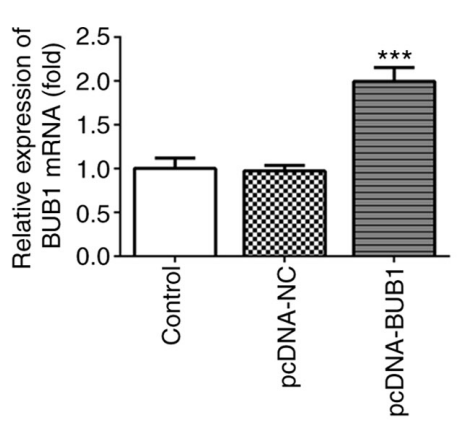

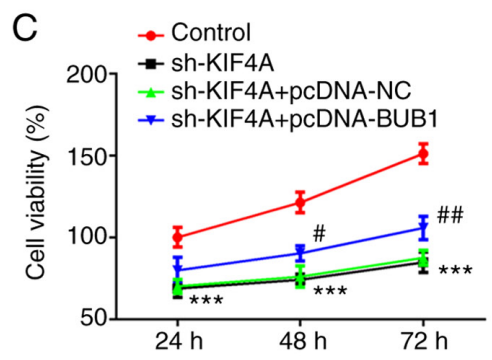

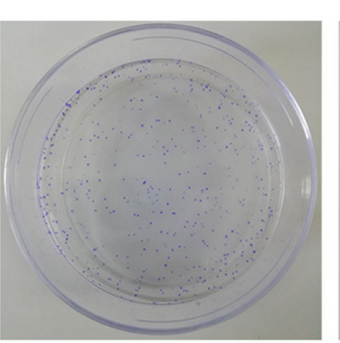

sh-KIF4A
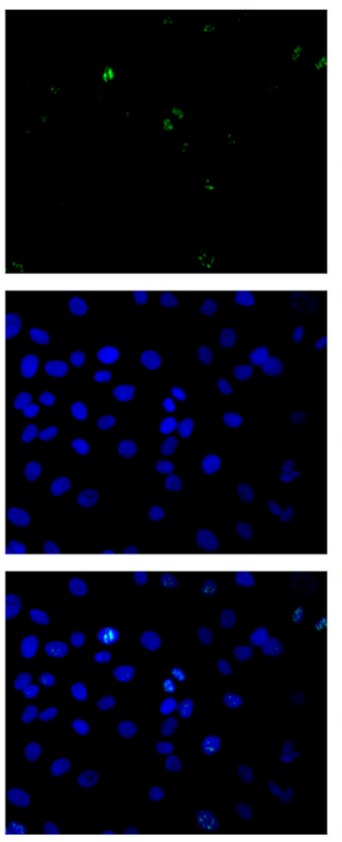

sh-KIF4A

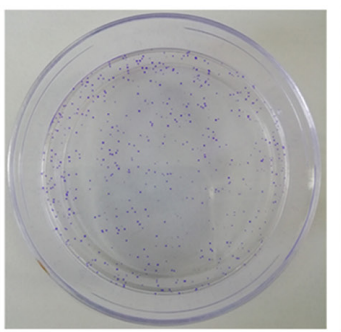

sh-KIF4A+pcDNA-NC
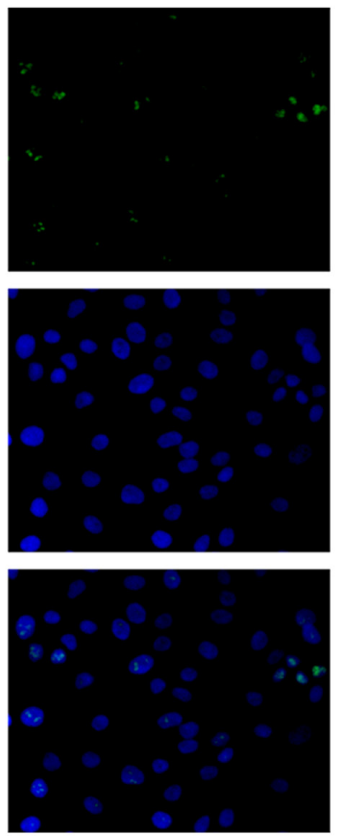

sh-KIF4A+pcDNA-NC

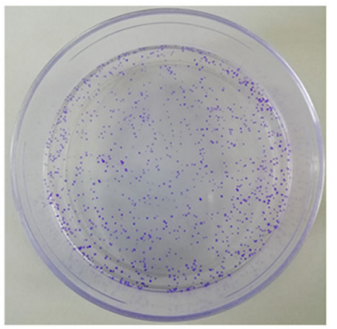

sh-KIF4A+pcDNA-BUB1
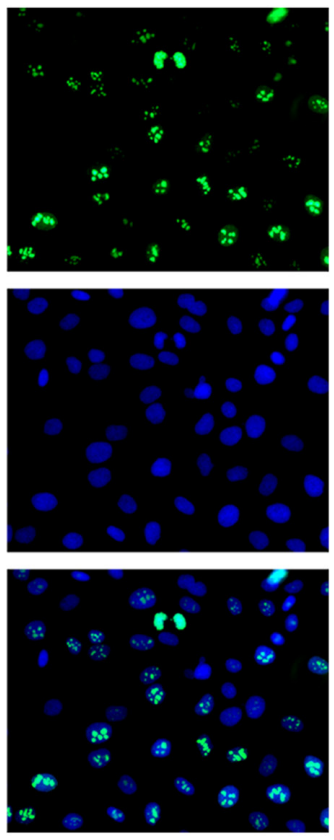

sh-KIF4A+pcDNA-BUB1

Figure 6. BUB1 overexpression reverses KIF4A-mediated inhibitory effects on cell proliferation. OVCAR3 cells were transfected with pcDNA-NC, pcDNABUB1, sh-KIF4A, sh-KIF4A + pcDNA-NC or sh-KIF4A + pcDNA-BUB1. BUB1 (A) protein and (B) mRNA expression levels were measured via western blotting and reverse transcription-quantitative PCR, respectively. (C) Cell viability was assessed by performing Cell Counting Kit-8 assays. Cell colony formation was (D) determined by performing colony formation assays. Magnification, x1. (E) Ki67 expression was detected via immunofluorescence. Magnification, x 400. ${ }^{*} \mathrm{P}<0.05$ and ${ }^{* * *} \mathrm{P}<0.001$ vs. pcDNA-NC or control; ${ }^{*} \mathrm{P}<0.05$ and ${ }^{\# \#} \mathrm{P}<0.01$ vs. sh-KIF4A + pcDNA-NC. BUB1, budding uninhibited by benzimidazoles 1 ; KIF4A, kinesin family member 4A; NC, negative control; sh, short hairpin RNA.

progression. In the present study, the results demonstrated that KIF4A expression was significantly upregulated in ovarian cancer cell lines compared with IOSE-80 cells. Moreover, compared with the shRNA-NC group, KIF4A knockdown significantly inhibited cell viability, colony formation and migration, and markedly promoted cell apoptosis, revealing the potential value of KIF4A in regulating the tumorigenesis of ovarian cancer.

BUB1 has been recognized as an oncogene in several types of cancer. It has been reported that BUB1 downregulation can 

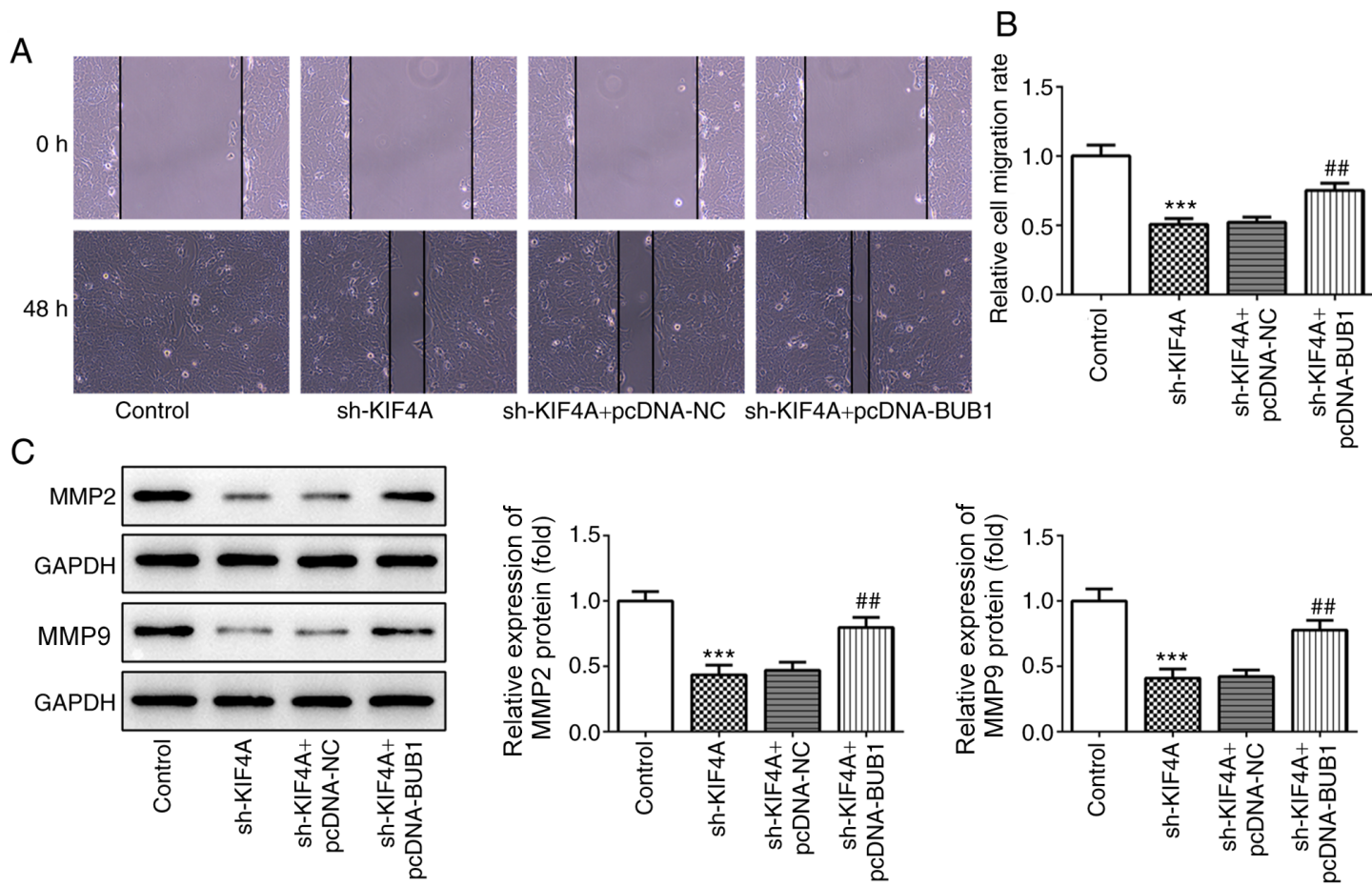

Figure 7. BUB1 overexpression reverses KIF4A-mediated inhibitory effects on cell migration. Cell migration was (A) detected by performing wound healing assays and (B) quantified. Magnification, x100. (C) Expression levels of migration-related proteins (MMP2 and MMP9) were detected via western blotting. ${ }^{* * * *} \mathrm{P}<0.001$ vs. control; ${ }^{\# \#} \mathrm{P}<0.01$ vs. sh-KIF4A + pcDNA-NC. BUB1, budding uninhibited by benzimidazoles 1; KIF4A, kinesin family member 4A; MMP, matrix metallopeptidase; sh, short hairpin RNA; NC, negative control.
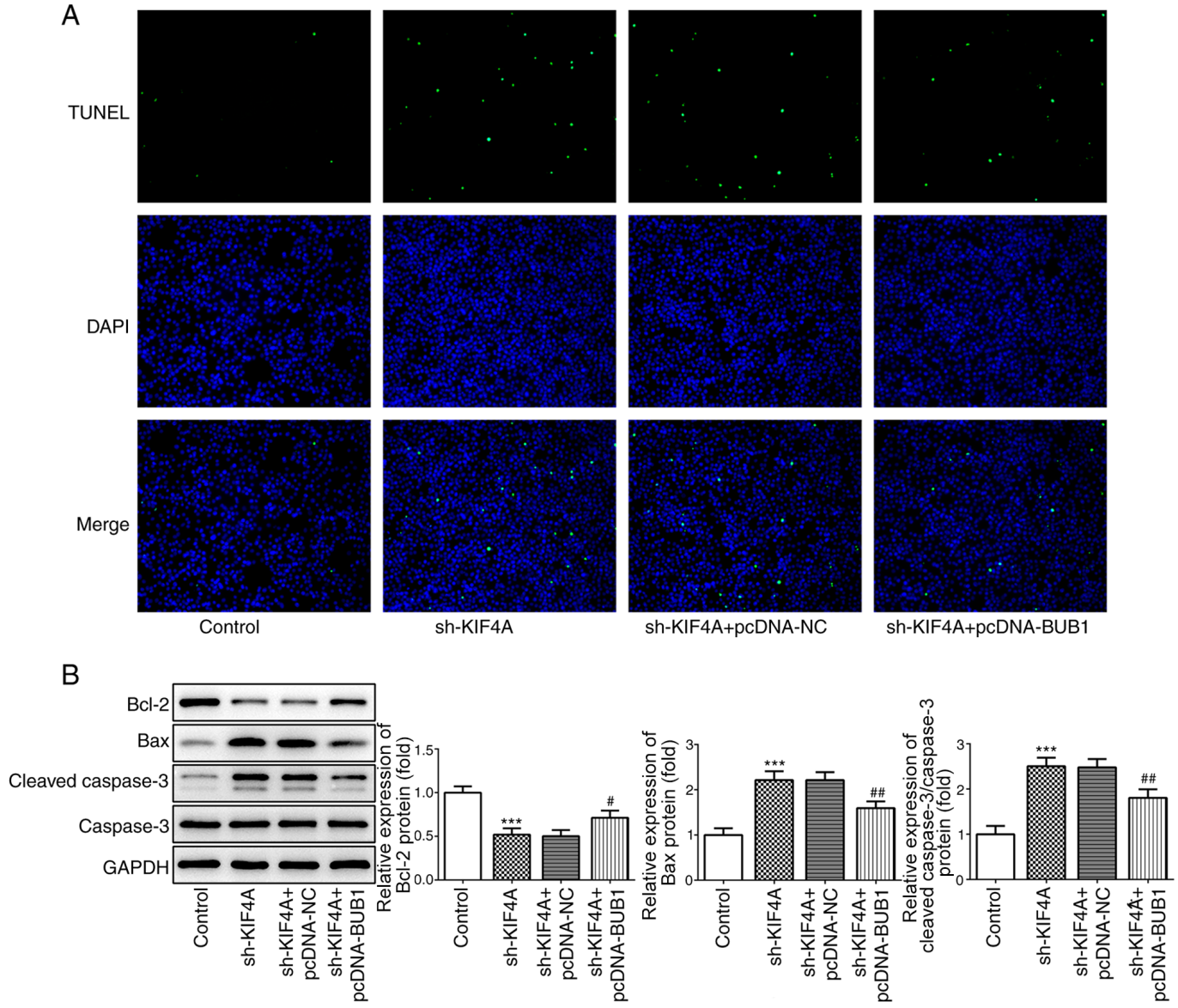

sh-KIF4A

sh-KIF4A+pcDNA-NC

sh-KIF4A+pcDNA-BUB1

Figure 8. BUB1 overexpression reverses KIF4A-induced cell apoptosis. (A) TUNEL assays were performed to assess cell apoptosis. Magnification, x200. (B) Apoptosis-related protein expression levels were determined via western blotting and semi-quantified. ${ }^{* * *} \mathrm{P}<0.001$ vs. control; ${ }^{\#} \mathrm{P}<0.05$ and ${ }^{\# \#} \mathrm{P}<0.01$ vs. sh-KIF4A + pcDNA-NC. BUB1, budding uninhibited by benzimidazoles 1; KIF4A, kinesin family member 4A; sh, short hairpin RNA; NC, negative control. 
inhibit cell proliferation, migration and invasion, and increase the rate of apoptosis in hepatocellular carcinoma cells (25). Clinical gene analysis identified a close association between BUB1 expression and poor clinical outcomes in patients with breast cancer with metastasis (26). Additionally, BUB1 has been reported to serve as a key proliferation-associated gene in non-small cell lung cancer (27). The present study demonstrated that BUB1 mRNA and protein expression levels were significantly increased in ovarian cancer cell lines compared with IOSE- 80 cells. In addition, the co-immunoprecipitation assay results further demonstrated the interaction between KIF4A and BUB1. The subsequent functional experiments revealed that BUB1 overexpression weakened KIF4A knockdown-mediated inhibitory effects on cell viability, colony formation and migration, and KIF4A knockdown-induced cell apoptosis, indicating a potential mechanism underlying the molecular action of KIF4A in ovarian cancer.

In conclusion, to the best of our knowledge, the present study was the first to suggest that aberrant KIF4A expression might regulate the progression of ovarian cancer. Compared with the shRNA-NC group, KIF4A knockdown suppressed ovarian cancer cell viability, colony formation and migration, and promoted ovarian cancer cell apoptosis via downregulating BUB1 expression. The results of the present study suggested that therapeutic strategies targeting the KIF4A/BUB1 axis might be beneficial for the treatment of ovarian cancer. A key limitation of the present study was the lack of investigation of the role of KIF4A in ovarian cancer using other cell lines. Therefore, future studies should use additional cell lines to verify the results of the present study.

\section{Acknowledgements}

Not applicable.

\section{Funding}

No funding was received.

\section{Availability of data and materials}

The datasets used and/or analyzed during the current study are available from the corresponding author on reasonable request.

\section{Authors' contributions}

LY designed the study, performed the experiments, interpreted the data and critically revised the manuscript. WJ performed the experiments, analyzed the data and drafted the manuscript. All authors read and approved the final manuscript. LY was accountable for the work in ensuring that questions related to the integrity of any part of the work are appropriately investigated and resolved. LY and WJ confirm the authenticity of all the raw data. All authors read and approved the final manuscript.

\section{Ethics approval and consent to participate}

Not applicable.

\section{Patient consent for publication}

Not applicable.

\section{Competing interests}

The authors declare that they have no competing interests.

\section{References}

1. Webb PM and Jordan SJ: Epidemiology of epithelial ovarian cancer. Best Pract Res Clin Obstet Gynaecol 41: 3-14, 2017.

2. Stewart C, Ralyea C and Lockwood S: Ovarian Cancer: An Integrated Review. Semin Oncol Nurs 35: 151-156, 2019.

3. Vargas AN: Natural history of ovarian cancer. Ecancermedicalscience 8: 465, 2014.

4. Wang L, Yan W, Li X, Liu Z, Tian T, Chen T, Zou L and Cui Z: S100A10 silencing suppresses proliferation, migration and invasion of ovarian cancer cells and enhances sensitivity to carboplatin. J Ovarian Res 12: 113, 2019.

5. Rath O and Kozielski F: Kinesins and cancer. Nat Rev Cancer 12: 527-539, 2012.

6. Ha MJ, Yoon J, Moon E, Lee YM, Kim HJ and Kim W: Assignment of the kinesin family member 4 genes (KIF4A and KIF4B) to human chromosome bands Xq13.1 and 5q33.1 by in situ hybridization. Cytogenet Cell Genet 88: 41-42, 2000.

7. Mazumdar M, Sundareshan S and Misteli T: Human chromokinesin KIF4A functions in chromosome condensation and segregation. J Cell Biol 166: 613-620, 2004.

8. Hu CK, Coughlin M, Field CM and Mitchison TJ: KIF4 regulates midzone length during cytokinesis. Curr Biol 21: 815-824, 2011.

9. Kurasawa Y, Earnshaw WC, Mochizuki Y, Dohmae N and Todokoro K: Essential roles of KIF4 and its binding partner PRC1 in organized central spindle midzone formation. EMBO J 23: 3237-3248, 2004.

10. Hou PF, Jiang T, Chen F, Shi PC, Li HQ, Bai J and Song J: KIF4A facilitates cell proliferation via induction of p21-mediated cell cycle progression and promotes metastasis in colorectal cancer. Cell Death Dis 9: 477, 2018.

11. Xue D, Cheng P, Han M, Liu X, Xue L, Ye C, Wang K and Huang J: An integrated bioinformatical analysis to evaluate the role of KIF4A as a prognostic biomarker for breast cancer. OncoTargets Ther 11: 4755-4768, 2018.

12. Gao H, Chen X, Cai Q, Shang Z and Niu Y: Increased KIF4A expression is a potential prognostic factor in prostate cancer. Oncol Lett 15: 7941-7947, 2018.

13. Hou G, Dong C, Dong Z, Liu G, Xu H, Chen L, Liu L, Wang H and Zhou W: Upregulate KIF4A Enhances Proliferation, Invasion of Hepatocellular Carcinoma and Indicates poor prognosis Across Human Cancer Types. Sci Rep 7: 4148, 2017.

14. Yang D, He Y, Wu B, Deng Y, Wang N, Li M and Liu Y: Integrated bioinformatics analysis for the screening of hub genes and therapeutic drugs in ovarian cancer. J Ovarian Res 13: 10, 2020.

15. Bolanos-Garcia VM and Blundell TL: BUB1 and BUBR1: Multifaceted kinases of the cell cycle. Trends Biochem Sci 36: 141-150, 2011.

16. Fu X, Chen G, Cai ZD, Wang C, Liu ZZ, Lin ZY, Wu YD, Liang YX, Han ZD, Liu JC, et al: Overexpression of BUB1B contributes to progression of prostate cancer and predicts poor outcome in patients with prostate cancer. OncoTargets Ther 9: 2211-2220, 2016.

17. Stahl D, Braun M, Gentles AJ, Lingohr P, Walter A, Kristiansen G and Gütgemann I: Low BUB1 expression is an adverse prognostic marker in gastric adenocarcinoma. Oncotarget 8: 76329-76339, 2017.

18. von Mering C, Huynen M, Jaeggi D, Schmidt S, Bork P and Snel B: STRING: A database of predicted functional associations between proteins. Nucleic Acids Res 31: 258-261, 2003.

19. Feng H, Gu ZY, Li Q, Liu QH, Yang XY and Zhang JJ: Identification of significant genes with poor prognosis in ovarian cancer via bioinformatical analysis. J Ovarian Res 12: 35, 2019.

20. Livak KJ and Schmittgen TD: Analysis of relative gene expression data using real-time quantitative PCR and the 2(-Delta Delta C(T)) Method. Methods 25: 402-408, 2001.

21. Wang $X$ and Chen T: CUL4A regulates endometrial cancer cell proliferation, invasion and migration by interacting with CSN6. Mol Med Rep 23: 23, 2021. 
22. Zhang Y, Yang X, Ge X and Zhang F: Puerarin attenuates neurological deficits via Bcl-2/Bax/cleaved caspase-3 and Sirt3/SOD2 apoptotic pathways in subarachnoid hemorrhage mice. Biomed Pharmacother 109: 726-733, 2019.

23. Holschneider $\mathrm{CH}$ and Berek JS: Ovarian cancer: Epidemiology, biology, and prognostic factors. Semin Surg Oncol 19: 3-10, 2000

24. Maringe C, Walters S, Butler J, Coleman MP, Hacker N, Hanna L, Mosgaard BJ, Nordin A, Rosen B, Engholm G, et al; ICBP Module 1 Working Group: Stage at diagnosis and ovarian cancer survival: Evidence from the International Cancer Benchmarking Partnership. Gynecol Oncol 127: 75-82, 2012.

25. Xu B, Xu T, Liu H, Min Q, Wang S and Song Q: MiR-490-5p suppresses cell proliferation and invasion by targeting BUB1 in hepatocellular carcinoma cells. Pharmacology 100: 269-282, 2017.
26. Tang D, Zhao X, Zhang L, Wang Z and Wang C: Identification of hub genes to regulate breast cancer metastasis to brain by bioinformatics analyses. J Cell Biochem 120: 9522-9531, 2019.

27. Pabla S, Conroy JM, Nesline MK, Glenn ST, PapanicolauSengos A, Burgher B, Hagen J, Giamo V, Andreas J, Lenzo FL, et al: Proliferative potential and resistance to immune checkpoint blockade in lung cancer patients. J Immunother Cancer 7: 27, 2019.

(i) (5) This work is licensed under a Creative Commons Attribution-NonCommercial-NoDerivatives 4.0 International (CC BY-NC-ND 4.0) License. 